\title{
Measurement and Correlation of LLE Data for the Ternary System Water+Phosphoric Acid+1-Pentanol at $278.2 \mathrm{~K}$ and $288.2 \mathrm{~K}$
}

\author{
Sina Shekarsaraee*, Khadijeh Kazemi
}

Department of Chemistry, University of Guilan, P.O. Box: 41335-19141, Rasht, Iran

\section{A R T I C L E I N F O}

Received: 23 October 2019

Revised: 29 November 2019

Accepted: 08 December 2019

Available online: 10 December 2019

\section{K E Y W O R D S}

Phosphoric acid

Liquid-liquid equilibrium

Thermodynamic model

LSER approach

\section{A B S T R A C T}

In this study, experimental tie-line data analysis was conducted for the ternary system (water+phosphoric acid+1-pentanol) at $278.2 \mathrm{~K}$ and $288.2 \mathrm{~K}$ and atmospheric pressure. The compositions of equilibrium phases were determined using the acid-base and the Karl Fisher titration methods and mass balance calculations. Reliability of the experimental data was investigated using the Othmer-Tobias and Hand equations. The UNIQUAC thermodynamic model was applied for correlation of the equilibrium tie-line points. The experimental tie-lines were satisfactorily regressed using the thermodynamic model (\%rmsd=2.48). Distribution coefficients and separation factors were determined over the biphasic area. Separation factors were greater than one in all the investigated feeds at the studied temperatures that guarantees the successful separation process. The Kamlet-Taft parameters were applied for the LSER modeling of the obtained distribution coefficients and separation factors. The effect of temperature on extraction process was investigated by adding a modification term in Kamlet-Taft equation. The ternary system revealed good fittings with the modified LSER model. The results showed that, the temperature decrement had positive effect on the extraction ability of the 1-pentanol for separating phosphoric acid from aqueous solution.

G RA P H I C A L A B S T RACT

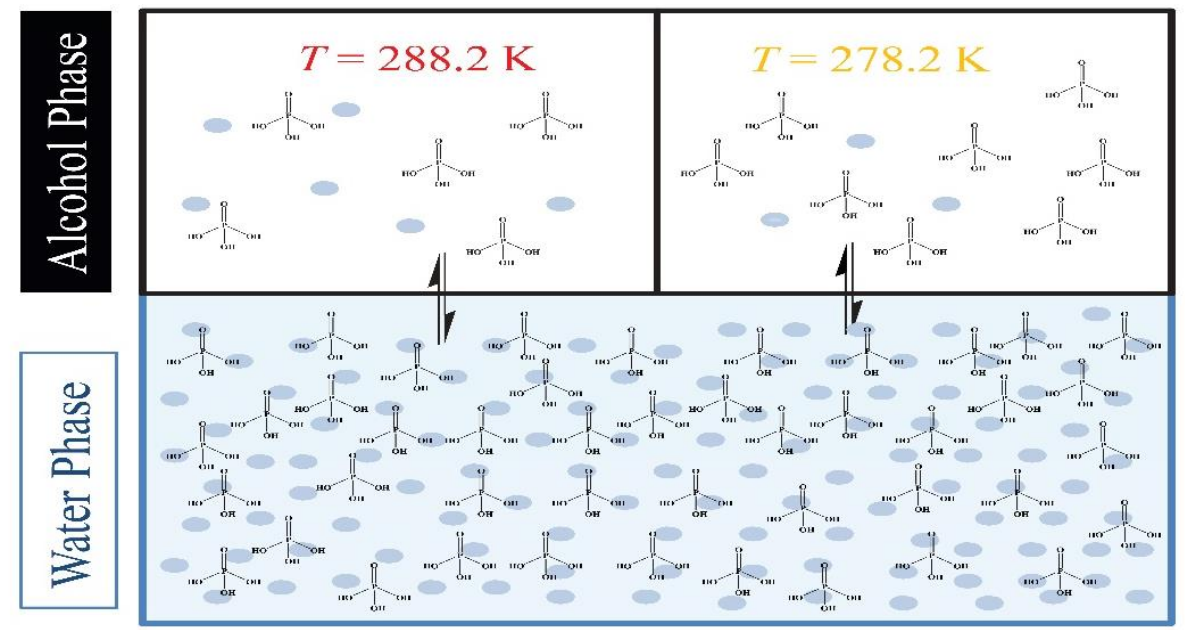

* Corresponding author's E-mail address: shekarsaraee@guilan.ac.ir 


\section{Introduction}

Phosphoric acid (PA) has a broad variety of uses and the most ordinary method of its production is wet process (in comparison with thermal and dry kiln process); however, the produced acid is a dilute aqueous solution with various impurities. Pure PA has many applications in food industry, production of phosphate fertilizers, and phosphate fuel cells. Liquid-liquid extraction is a regular method for extracting polar acids including, phosphoric acid, formic acid, and lactic acid from water solution [1-11].

Alcohols, esters, ketones and hydrocarbons are the solvents used for extracting phosphoric acid from dilute water solutions [12-26]. Between reported solvents, alcohols showed better results for extraction of PA from water. In this work, 1-pentanol or amyl alcohol (POH) was selected for purification of PA from aqueous solution and liquid-liquid equilibrium studies were done for related ternary systems. POH has effective properties such as suitable functional group, water immiscibility and high boiling point that make it a high quality extractant for recovering of PA from water. LLE data for the system (water+phosphoric acid+1-pentanol) has recently been reported by Ghanadzadeh $e t$ al. [25] over the temperature range of $298.2 \mathrm{~K}$ to $318.2 \mathrm{~K}$ but lower temperatures have not been investigated by any researcher.

This work presents valuable LLE data for separation and extraction of phosphoric acid from aqueous solutions and to the best of our knowledge, no such data have been published before. Phase diagrams containing tie-line data were measured at $278.2 \mathrm{~K}$ and $288.2 \mathrm{~K}$. The Othmer-Tobias [27] and Hand [28] correlation equations were then applied to prove the reliability of obtained tie-line data. The UNIQUAC method of Abrams and Prausnitz [29] was also used for thermodynamic modeling and correlating the tie-line points.
The main aim of this study was to investigate the effect of temperature decreasing on extraction ability of $\mathrm{POH}$ and presenting a temperature dependent equation for prediction of extraction capacity of the studied solvent in a wide temperature range from $278.2 \mathrm{~K}$ to $318.2 \mathrm{~K}$. For this reason, distribution coefficients of phosphoric acid $\left(D_{2}\right)$ and separation factors (S) were determined to illuminate the capacity of the solvent for separation of phosphoric acid from aqueous phase. Finally, computed distribution coefficients and separation factors were fitted to the Kamlet-Taft [30] LSER model. In this model, solvent dipolarity/polarizability, hydrogen-bond donor acidity, hydrogen-bond acceptor basicity, discontinuous polarizability correction terms have been presented for investigation of solute property that are $D_{2}$ and $S$ in this research. A modification term for analyzing the temperature effect was also inserted in the LSER equation.

\section{Experimental}

\section{Materials}

1-Pentanol and phosphoric acid were purchased from Merck Company and used without any farther purification. The mass fraction purities of the chemicals were of 0.99 and 0.85 , respectively. Purity of the acid was verified through acidimetric titration with 0.5 $\mathrm{mol} / \mathrm{L} \mathrm{NaOH}$. HPLC-grade water was applied throughout all experiments.

\section{Apparatus and procedure}

A Metrohm-870 KF Titrino plus Karl-Fisher titrator was applied in this study. Temperature of instruments was kept constant with an accuracy of $\pm 0.1 \mathrm{~K}$, which was checked by a Testo-735digital thermometer. All the mixtures were weighed via a Precisa electronic analytical balance (model LS120A) with an accuracy of $\pm 0.0002 \mathrm{~g}$. 
Tie-line data of the ternary system (water+ phosphoric acid+1-pentanol) were obtained at $\mathrm{T}=278.2 \mathrm{~K}$ and $288.2 \mathrm{~K}$. Ternary mixtures with known compositions of water, $\mathrm{PA}$, and $\mathrm{POH}$ were first prepared in an equilibrium glass cell $(50 \mathrm{~mL})$. The mixtures were then vigorously stirred by a magnetic stirrer for $2 \mathrm{~h}$, and after that settled for $2 \mathrm{~h}$ until two clear layers were formed and separated from each other. Preliminary experiments confirmed that these times are sufficient to reach the equilibrium. Samples of both the alcoholic-rich and the aqueous-rich layers were ejected by a glass syringe from upper and lower phases, respectively.

Acid compositions in both the layers ( $w_{21}$ for aqueous phase and $w_{23}$ for organic phase) were measured by acid-base titration. Mass fraction of water in the organic $\left(w_{13}\right)$ and aqueous $\left(w_{11}\right)$ phases were measured by Karl-Fisher titrations [31]. Mass fraction of 1-pentanol in each layer (i.e., $w_{31}$ and $w_{33}$ for water and alcohol phases, orderly) was determined using the equation of $\sum w_{i}=1$. Estimated standard uncertainty of all obtained compositions was better than \pm 0.005 .

\section{Results and discussion}

Experimental LLE results

Tie-line data of the ternary system (water+phosphoric acid+1-pentanol) were determined at $278.2 \mathrm{~K}$ and $288.2 \mathrm{~K}$ and ambient pressure. LLE data and phase diagram of the studied ternary system are presented in Table 1 and Figure 1, respectively. Figure 1 shows that the solubility of PA in water is more than in $\mathrm{POH}$ and this behavior is regular because phosphoric acid is an inorganic acid and tends to solve in water more than any organic solvent. The other important point of Figure 1 is determining the biphasic area (the area in which mixtures form two phases). Figure 1 shows that biphasic area is very large, causing the extraction process that could be done in less stages.

Table 1. Experimental tie-line data in mass fraction and Separation factors (S) and distribution coefficients of PA $\left(D_{2}\right)$ and water $\left(D_{1}\right)$ for (water+phosphoric acid+1-pentanol) at T $=278.2 \mathrm{~K}$ and 288.2 K and $101.3 \mathrm{kPa}^{\mathrm{a}}$

\begin{tabular}{cccccccccc}
$\mathrm{T}(\mathrm{K})$ & $w_{11}$ & $w_{21}$ & $w_{31}$ & $w_{13}$ & $w_{23}$ & $w_{33}$ & $D_{1}$ & $D_{2}$ & $S$ \\
& 0.770 & 0.221 & 0.009 & 0.106 & 0.037 & 0.857 & 0.138 & 0.167 & 1.22 \\
278.2 & 0.698 & 0.293 & 0.009 & 0.107 & 0.073 & 0.820 & 0.173 & 0.249 & 1.44 \\
& 0.642 & 0.348 & 0.010 & 0.108 & 0.119 & 0.773 & 0.168 & 0.342 & 2.03 \\
& 0.564 & 0.426 & 0.010 & 0.108 & 0.168 & 0.724 & 0.191 & 0.394 & 2.06 \\
& 0.524 & 0.465 & 0.011 & 0.110 & 0.198 & 0.692 & 0.210 & 0.426 & 2.03 \\
& 0.500 & 0.499 & 0.001 & 0.112 & 0.239 & 0.649 & 0.224 & 0.479 & 2.14 \\
& 0.773 & 0.216 & 0.011 & 0.109 & 0.033 & 0.858 & 0.141 & 0.153 & 1.08 \\
& 0.699 & 0.289 & 0.012 & 0.111 & 0.066 & 0.823 & 0.159 & 0.228 & 1.44 \\
& 0.631 & 0.357 & 0.012 & 0.112 & 0.109 & 0.779 & 0.177 & 0.305 & 1.72 \\
& 0.565 & 0.423 & 0.012 & 0.112 & 0.158 & 0.730 & 0.198 & 0.374 & 1.88 \\
& 0.518 & 0.469 & 0.013 & 0.114 & 0.186 & 0.700 & 0.220 & 0.397 & 1.80 \\
& 0.486 & 0.501 & 0.013 & 0.114 & 0.226 & 0.660 & 0.235 & 0.451 & 1.92 \\
\hline
\end{tabular}

a Standard uncertainties $\mathrm{u}$ are $\mathrm{u}(\mathrm{T})=0.1 \mathrm{~K}, \mathrm{u}(P)=0.6 \mathrm{kPa}, \mathrm{u}(w)=0.005$ 
Figure 1. Ternary phase diagram for LLE of [Water (1)+Phosphoric Acid (2)+1Pentanol (3)] at $\mathrm{T}=278.2 \mathrm{~K}$ and $288.2 \mathrm{~K}$; (O) experimental tie-lines at $288.2 \mathrm{~K}$ and $(\square)$ at $278.2 \mathrm{~K},(\Delta)$ UNIQUAC calculated points at $288.2 \mathrm{~K}$ and $(\diamond)$ at $278.2 \mathrm{~K}$

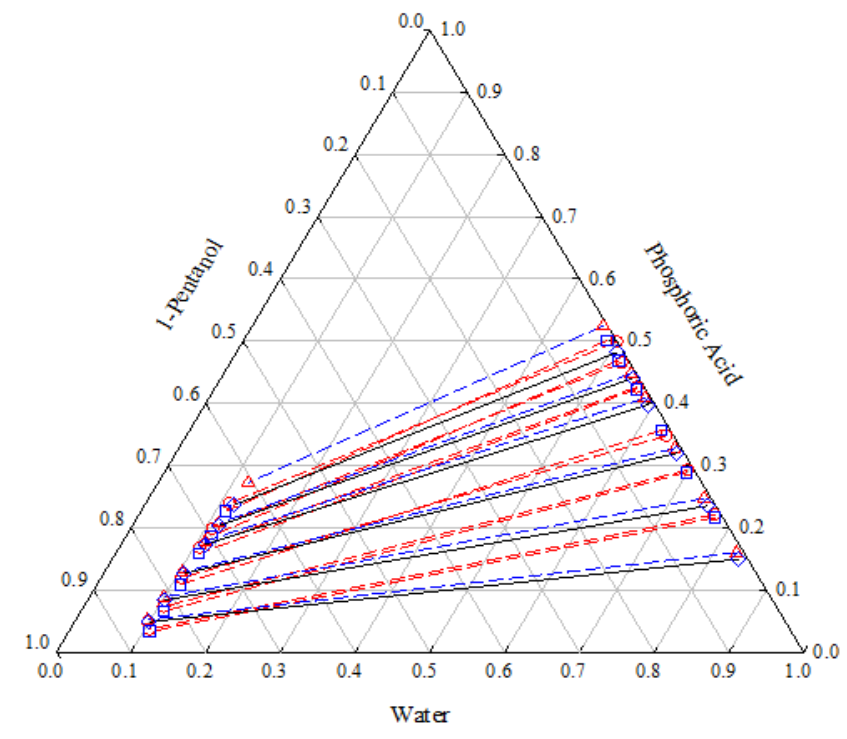

In this research study, quality, reliability and consistency of obtained tie-line points were investigated using the correlation of measured data with Othmer-Tobias (Equation 1) [27] and Hand (Equation 2) [28].

$$
\begin{aligned}
& \ln \left(\frac{\left(1-w_{33}\right)}{w_{33}}\right)=A+B \ln \left(\frac{\left(1-w_{11}\right)}{w_{11}}\right) \\
& \ln \left(\frac{w_{21}}{w_{11}}\right)=A^{\prime}+B^{\prime} \ln \left(\frac{w_{23}}{w_{33}}\right)
\end{aligned}
$$

Where $A, B, A^{\prime}$, and $B^{\prime}$ are parameters of the Othmer-Tobias and the Hand correlation equations, orderly. Othmer-Tobias and Hand plots are presented in Figure 2. Regression equations are also listed in the figure. Nearness of $\mathrm{R}$ square factor to 1 shows linearity of the plots and in this work proves a high degree of consistency and quality of the measured tielines.

For investigating the ability of the selected solvent $(\mathrm{POH})$ for extraction of $\mathrm{PA}$, distribution coefficients of water $\left(D_{1}=\frac{w_{13}}{w_{11}}\right)$ and PA $\left(D_{2}=\right.$ $\left.\frac{w_{23}}{w_{21}}\right)$ and separation factors $\left(S=\frac{D_{2}}{D_{1}}\right)$ were determined using the obtained tie-line points (Table 1). The plots of determined separation factors and distribution coefficients of PA as a function of mass fraction of the acid in aqueous layer are presented in Figure 3. All separation factors shown in the figure are larger than 1 which indicates that PA could be successfully separated from the water by 1-pentanol. Distribution coefficients are not necessary to be larger than one but the larger $D_{2}$ the less solvent consumption.

\section{Thermodynamic modeling}

Experimental LLE points could be correlated by UNIQUAC model of Abrams and Prausnitz [29]. At liquid-liquid equilibrium, the composition of the two phases (upper and lower phases) could be determined by using of the following equations.

$$
\begin{aligned}
& \left(\gamma_{i} x_{i}\right)^{1}=\left(\gamma_{i} x_{i}\right)^{2} \\
& \sum x_{i}^{1}=\sum x_{i}^{2}=1
\end{aligned}
$$

Where $\gamma_{i}^{1}$ and $\gamma_{i}^{2}$ are the corresponding activity coefficients of component $i$ in phase 1 and phase 2 (upper and lower phases), orderly. $x_{i}^{1}$ and $x_{i}^{1}$ are the mole fractions of component $i$ in the mixture and in phases 1 and 2, orderly. Equations 1 and 2 are solved for the mole fraction $(x)$ of component $i$ in the two liquid phases. 
Figure 2. The Othmer-Tobias and the Hand plots of the [Water (1)+ Phosphoric Acid (2)+1-Pentanol (3)) ternary system at $288.2 \mathrm{~K}$; (O) Hand Plot, $(\square)$ Othmer-Tobias Plot and at $278.2 \mathrm{~K}(\Delta)$ Hand Plot, $(\diamond)$ Othmer-Tobias Plot; $\left(\frac{a}{b}\right)=\frac{w_{23}}{w_{33}}$ or $\frac{1-w_{11}}{w_{11}}$ and $\left(\frac{c}{d}\right)=\frac{w_{21}}{w_{11}}$ or $\frac{1-w_{33}}{w_{33}}$ for Hand and Othmer-Tobias equations, orderly

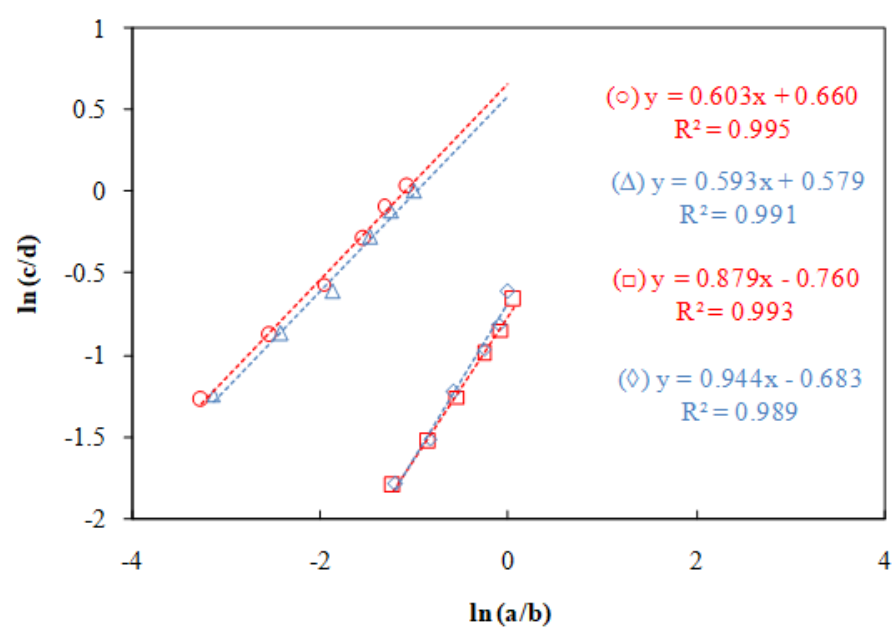

Figure 3. Plot of the separation factor (S) and distribution coefficient of PA $\left(D_{2}\right)$ as a function of mass fraction of $\mathrm{PA}$ in the aqueous phase; separation factor $(\square)$ at $288.2 \mathrm{~K}$ and $(\diamond)$ $278.2 \mathrm{~K}$, distribution coefficient $(\mathrm{O})$ at $288.2 \mathrm{~K}$ and $(\Delta) 278.2 \mathrm{~K}$

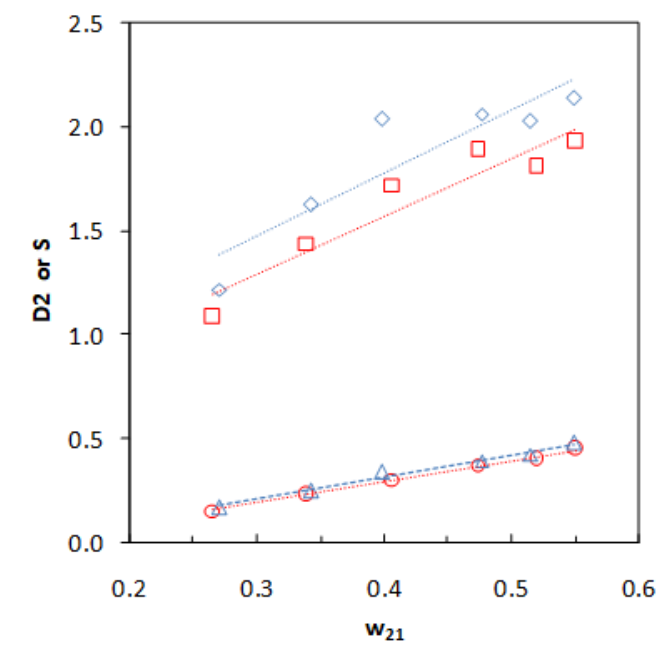

The UNIQUAC model (universal quasichemical model) for excess Gibbs energy $\left(G^{E}\right)$ is given as [29]:

$\ln \gamma_{i}^{c}=\ln \left(\frac{\Phi_{i}}{x_{i}}\right)+\frac{z}{2} q_{i} \ln \left(\frac{\theta_{i}}{\Phi_{i}}\right)+l_{t}-\frac{\phi_{i}}{x_{i}} \sum_{j=1}^{c} x_{j} l_{j}$

$$
\frac{G^{E}}{R T}=\sum_{i=1}^{3} x_{i} \ln \left(\frac{\Phi_{i}}{x_{i}}\right)+5 \sum_{i=1}^{3} q_{i} x_{i} \ln \left(\frac{\theta_{i}}{\Phi_{i}}\right)-\sum_{i=1}^{3} q_{i} x_{i} \ln \left(\sum_{j=1}^{n} \theta_{j} \tau_{j i}\right)
$$

$$
\ln \gamma_{i}^{r}=q_{i}\left[1-\ln \left(\sum_{j=1}^{c} \theta_{j} \tau_{j i}\right)-\sum_{j=1}^{c}\left(\frac{\theta_{j} \tau_{i j}}{\sum_{k=1}^{c} \theta_{k} \tau_{k j}}\right)\right]
$$

In this model, the logarithm of the activity coefficient is assumed to be the sum of two contributions.

$$
\ln \gamma_{i}=\ln \gamma_{i}^{c}+\ln \gamma_{i}^{r}
$$

The combinational $\left(\gamma_{i}^{c}\right)$ and residual parts $\left(\gamma_{i}^{r}\right)$ of the activity coefficient could be mentioned as follows:

Here $\tau_{i j}$ is adjustable parameter in the UNIQUAC equation. The parameter $\Phi_{\mathrm{i}}$ (segment fraction) and $\theta_{\mathrm{i}}$ (area fraction) are given by the following equations:

$$
\Phi_{i}=\frac{x_{i} r_{i}}{\sum_{i=1}^{c} x_{i} r_{i}} \theta_{i}=\frac{x_{i} q_{i}}{\sum_{i=1}^{c} x_{i} q_{i}}
$$




$$
\tau_{i j}=\left(-\frac{\Delta u_{i j}}{R T}\right)=\exp \left(-\frac{a_{i j}}{T}\right)
$$

The parameter $u_{i j}$ typifies the interaction energy between compounds $i$ and $j$. In the above equations, $a_{i j}$ and $a_{j i}$ are stated in $K$ and signify the energy interactions between an $i-j$ pair of molecules.

In the present work, the obtained tie-line points were correlated using the universal quasi-chemical (UNIQUAC) method of Abrams and Prausnitz [29]. Results of the correlation of the studied system are tabulated in Table 2 . The UNIQUAC structural parameters $r$ (the number of segments per molecules) and $\mathrm{q}$ (the relative surface area per molecules) were calculated from the number of molecular groups and the individual values of the van der Waals volume and area of the molecule by the Bondi method [32]. The computed $r$ and $q$ values applied for this study are presented in Table 2 .

To optimize the UNIQUAC model and achieve the binary interaction parameters, the objective function developed by Sorensen [33] was used. This function is the summation of the squares of dissimilarities between the experimental and correlated tie-line data. The variation of experimental and correlated points could be seen in Figure 1. During the correlation process, the optimum UNIQUAC binary interaction parameters between each pair of components were determined (Table $3)$.

Table 2. The UNIQUAC structural parameters ( $\mathrm{r}$ and $\mathrm{q}$ ) for pure components and calculated UNIQUAC tie-line data in mass fraction for (water+phosphoric acid+1-pentanol) at $T=278.2 \mathrm{~K}$ and $288.2 \mathrm{~K}^{\mathrm{a}}$

\begin{tabular}{|c|c|c|c|c|c|}
\hline$w_{11}$ & $w_{21}$ & \multicolumn{2}{|c|}{$\mathrm{T}=278.2 \mathrm{~K}$} & $w_{23}$ & $w_{33}$ \\
\hline 0.830 & 0.160 & 0.010 & 0.096 & 0.052 & 0.852 \\
\hline 0.743 & 0.247 & 0.010 & 0.100 & 0.088 & 0.812 \\
\hline 0.664 & 0.327 & 0.009 & 0.104 & 0.128 & 0.767 \\
\hline 0.583 & 0.408 & 0.008 & 0.110 & 0.178 & 0.712 \\
\hline 0.545 & 0.448 & 0.008 & 0.113 & 0.207 & 0.680 \\
\hline 0.470 & 0.524 & 0.006 & 0.121 & 0.272 & 0.607 \\
\hline \multicolumn{6}{|c|}{$\mathrm{T}=288.2 \mathrm{~K}$} \\
\hline 0.839 & 0.149 & 0.012 & 0.100 & 0.049 & 0.852 \\
\hline 0.754 & 0.235 & 0.011 & 0.103 & 0.084 & 0.813 \\
\hline 0.670 & 0.320 & 0.011 & 0.108 & 0.126 & 0.767 \\
\hline 0.593 & 0.398 & 0.010 & 0.113 & 0.173 & 0.714 \\
\hline 0.551 & 0.440 & 0.009 & 0.116 & 0.203 & 0.681 \\
\hline 0.509 & 0.482 & 0.009 & 0.120 & 0.237 & 0.643 \\
\hline
\end{tabular}

a The UNIQUAC structural parameters $\mathrm{r}$ (and q) of water: 0.920 (1.400), phosphoric acid: 3.000 (4.000) and 1-pentanol: 4.60 (4.21)

Table 3. The UNIQUAC binary interaction parameters $\left({ }^{a_{i j}}\right.$ and ${ }^{a_{j i}}$ ) for the studied ternary system and rmsdvalues ${ }^{\mathrm{a}}$

\begin{tabular}{cccc} 
& $a_{i j}{ }^{a} / K$ & $a_{j i} / K$ & $r m s d^{c} \%$ \\
$1-2$ & 1697.82 & -5647.42 & \\
$1-3$ & -302.13 & -53.22 & 2.48 \\
$2-3$ & -2635.96 & 1464.79 & \\
\hline
\end{tabular}

${ }^{\mathrm{a}} a_{i j}=\frac{\left(u_{i j}-u_{j j}\right)}{R}$ for UNIQUAC model 
Root-mean square deviation (rmsd) was used to determine the quality of correlated data and validity of obtained interaction parameters. The following equation shows how rmsd could be determined from the dissimilarity between experimental and correlated tie-line points.

$r m s d=\sqrt{\frac{\sum_{k=1}^{n} \sum_{j=1}^{2} \sum_{i=1}^{3}\left(w_{i j k}^{e x p}-w_{i j k}^{c a l}\right)^{2}}{6 n}}$

Where $\mathrm{n}$ is the number of tie-line data and $w_{\mathrm{ijk}}^{\mathrm{exp}}$ and $w_{\mathrm{ijk}}^{\mathrm{cal}}$ present the experimental and correlated data. The subscript $\mathrm{i}, \mathrm{j}$ and $\mathrm{k}$ indexes components, layers and tie-line data $(\mathrm{k}=1,2, \ldots, \mathrm{n})$, orderly. The rmsd value of UNIQUAC model for the studied system at $\mathrm{T}=278.2 \mathrm{~K}$ and $288.2 \mathrm{~K}$ are given in Table 3 . The calculated rmsd value shows that the UNIQUAC model has had a good fitting with experimental data.

\section{LSER modeling}

The Kamlet-Taft's linear solvation energy relationship (LSER) model [30] was utilized for correlating the distribution coefficients and separation factors. The multi-parameter equation applied in this work, was developed by Kamlet, Abboud, Abraham and Taft [34]. In this study, a modified form of the Kamlet-Taft equation was used. The modification consists of addition of a dimensionless term as $T^{N}$ (normalized temperature) that describes temperature effect. $T^{N}$ is obtained by dividing the studied temperature to $T_{\text {base }}$ that is equal to $298.2 \mathrm{~K}$, the temperature at which the solvatochromic parameters are available. This modification term has been previously used for Katritzky LSER model [35]. For distribution coefficient $\left(D_{2}\right)$ and separation factor $(S)$, the equations will be as follows:

$\log D_{2}=\log D_{2}^{0}+c .\left(\pi^{*}+e . \delta\right)+a . \alpha+$ b. $\beta+d \cdot T^{N}$ $\log S=\log S^{0}+c^{\prime} \cdot\left(\pi^{*}+\mathrm{e}^{\prime} \cdot \delta\right)+a^{\prime} \cdot \alpha+$ $b^{\prime} \cdot \beta+d \cdot T^{N}$

$T^{N}=\frac{T}{T_{\text {base }}}$

The solvent dipolarity/polarizability, hydrogen-bond donor acidity, hydrogenbond acceptor basicity, discontinuous polarizability correction term (that is equal to zero for the studied solvents) and normalized temperature are presented as $\pi^{*}, \alpha, \beta, T^{N}$ and $\delta$, orderly, in equations 12 and 13. According to the above descriptions, the coefficients $e$ and $\mathrm{e}^{\prime}$ will be eliminated and the coefficients $a, a^{\prime}, b$, $b^{\prime}, c, c^{\prime}, d$ and $d^{\prime}$ are obtained from regression and depend on the solute properties. The values of the solvatochromic parameters $\alpha, \beta, \pi^{*}$ and $\delta$ $(0.84,0.86,0.40,0.00)$ were taken from reference [30]. The Excel Data analysis pack was applied to regress the obtained values. Experimental and correlated distribution coefficients and separation factors were reported in Table 4. The estimated parameters of LSER model and rmsd values are inserted in Table 5. The rmsd percents of the table show that LSER model greatly regressed the experimental data for both the studied and the published [25] temperatures. The coefficients of Table 5 show that the temperature has the same effect as the solvatochromic parameters in distribution coefficient changes but the opposite effect in separation factor alterations. The less rmsd values (close to zero) prove the closeness of experimental points to correlated data, while the proximity of $\mathrm{R}$ square values (Figure 4) to one establishes that the LSER model could greatly predict the trend of input data. 
Table 4. Comparison between experimental and LSER data for correlation of distribution coefficients $\left(D_{2}\right)$ and separation factors ${ }^{a}$

\begin{tabular}{|c|c|c|c|c|c|}
\hline$w_{3}($ feed $)$ & $\mathrm{T}(\mathrm{K})$ & $\log D_{2 \text { Exp. }}$ & $\log D_{2 \text { LSER }}$ & $\log S_{\text {Exp. }}$ & $\log S_{\mathrm{LSER}}$ \\
\hline 0.441 & 278.2 & -0.776 & -0.756 & 0.085 & 0.119 \\
\hline 0.417 & & -0.604 & -0.643 & 0.211 & 0.179 \\
\hline 0.394 & & -0.466 & -0.535 & 0.308 & 0.236 \\
\hline 0.365 & & -0.404 & -0.399 & 0.314 & 0.308 \\
\hline 0.353 & & -0.371 & -0.342 & 0.307 & 0.338 \\
\hline 0.341 & & -0.320 & -0.286 & 0.330 & 0.368 \\
\hline 0.439 & 288.2 & -0.816 & -0.787 & 0.035 & 0.062 \\
\hline 0.416 & & -0.641 & -0.676 & 0.158 & 0.122 \\
\hline 0.381 & & -0.515 & -0.508 & 0.236 & 0.214 \\
\hline 0.360 & & -0.428 & -0.408 & 0.275 & 0.269 \\
\hline 0.342 & & -0.402 & -0.321 & 0.256 & 0.317 \\
\hline 0.329 & & -0.346 & -0.259 & 0.284 & 0.351 \\
\hline 0.454 & $298.2^{\mathrm{a}}$ & -0.498 & -0.900 & 0.215 & -0.042 \\
\hline 0.420 & & -0.949 & -0.734 & -0.106 & 0.052 \\
\hline 0.397 & & -0.671 & -0.621 & 0.106 & 0.116 \\
\hline 0.373 & & -0.548 & -0.504 & 0.182 & 0.183 \\
\hline 0.360 & & -0.459 & -0.440 & 0.222 & 0.219 \\
\hline 0.340 & & -0.416 & -0.342 & 0.226 & 0.274 \\
\hline 0.454 & $308.2^{\mathrm{a}}$ & -0.364 & -0.941 & 0.235 & -0.106 \\
\hline 0.416 & & -0.529 & -0.752 & 0.159 & 0.005 \\
\hline 0.396 & & -1.034 & -0.652 & -0.206 & 0.063 \\
\hline 0.376 & & -0.690 & -0.552 & 0.074 & 0.121 \\
\hline 0.361 & & -0.586 & -0.478 & 0.130 & 0.165 \\
\hline 0.344 & & -0.501 & -0.393 & 0.164 & 0.214 \\
\hline 0.445 & $318.2^{\mathrm{a}}$ & -0.436 & -0.936 & 0.191 & -0.143 \\
\hline 0.416 & & -0.391 & -0.789 & 0.178 & -0.054 \\
\hline 0.392 & & -0.562 & -0.667 & 0.107 & 0.019 \\
\hline 0.369 & & -1.067 & -0.551 & -0.264 & 0.089 \\
\hline 0.350 & & -0.777 & -0.455 & -0.023 & 0.147 \\
\hline 0.337 & & -0.629 & -0.389 & 0.080 & 0.187 \\
\hline
\end{tabular}

Table 5. Estimated parameters of the LSER equations obtained by linear regression.

\begin{tabular}{|c|c|c|c|c|c|c|}
\hline Parameters & $\begin{array}{c}\log D_{2}^{0} \text { or } \\
\log S^{0}\end{array}$ & a or $a^{\prime}$ & $b$ or $b^{\prime}$ & c or c $c^{\prime}$ & $d$ or $d^{\prime}$ & $\%$ rmsd \\
\hline $\begin{array}{c}\text { For Distribution } \\
\text { Coefficients }\end{array}$ & 1.320 & -1.148 & -1.176 & -0.547 & -2.695 & 5.22 \\
\hline $\begin{array}{l}\text { For Separation } \\
\text { Factors }\end{array}$ & 1.215 & 0.760 & 0.778 & 0.362 & -4.220 & 5.26 \\
\hline
\end{tabular}


Figure 4. The linear plot of experimental points versus estimated points (a) distribution coefficients, (b) separation factors

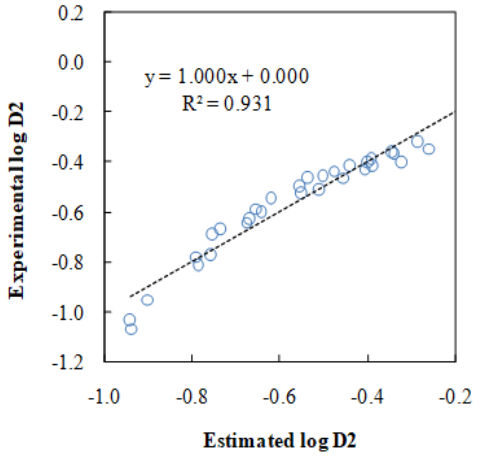

(a)

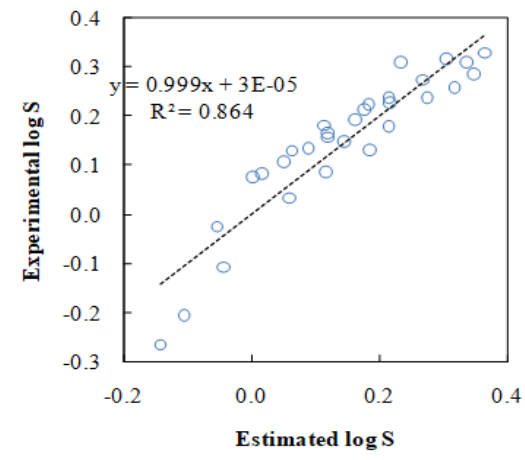

(b)

\section{Conclusion}

Experimental LLE points for the ternary system (water+phosphoric acid+1-pentanol) were measured at $278.2 \mathrm{~K}$ and $288.2 \mathrm{~K}$ and $101.3 \mathrm{kPa}$. The UNIQUAC model was applied for correlation of the obtained tieline points and calculating the binary interaction parameters of the investigated mixtures and the model produced acceptable results for the studied system. Separation factors and distribution coefficients were calculated for evaluation of solvent capacity. The calculated results showed that the separation factors for $\mathrm{POH}$ are greater than one for the studied acid concentration range in this study, proving that the solvent is able to purify the acid from aqueous solution. Temperature effect was also investigated using the literature and measured data and the results demonstrated that the temperature decreasing had positive effect on the extraction ability of the solvent. Finally, modified Kamlet-Taft LSER model was applied to correlate the distribution coefficients and separation factors. This modified model greatly fitted the experimental partition functions.

\section{Acknowledgement}

The authors are grateful to the University of Guilan for its support.

\section{Disclosure statement}

No potential conflict of interest was reported by the authors.

\section{References}

[1] P. Becker, Phosphates and phosphoric acid, raw materials, technology and economics of the wet process; 2nd Ed.; Marcel Dekker Inc.; New York, 1989, pp 37-64.

[2] S.V. Dorozhkin, Ind. Eng. Chem. Res., 1997, 36, 467-473.

[3] J.F. McCullough, L.L. Frederick, J. Agric. Food Chem., 1976, 24, 180-187.

[4] J.M. Marco, M.I. Galan, J. Costa, J. Chem. Eng. Data, 1988, 33, 211-214.

[5] M. Feki, M. Fourati, M.M. Chaabouni, H.F. Ayedi, Can. J. Chem. Eng., 1994, 72, 939944.

[6] S. Stenstrom, S. Wingefors, Can. J. Chem. Eng., 1988, 66, 248-257.

[8] R. Dhouib-Sahnoun, M. Feki, H.F. Ayedi, J. Chem. Eng. Data, 2002, 47, 861-866.

[9] F. Ruiz, M.I. Galan, N. Boluda, Fluid Phase Equilib., 1998, 146, 175-185.

[10] K. Bahrpaima, A.R. Bijanzadeh, M. Behzadi, Phys. Chem. Res., 2017, 5, 125134.

[11] H. Ghanadzadeh Gilani, A. Ghanadzadeh Gilani, F. Borji Peydeh, S.L. Seyed Saadat, S. Ahmadifar, Phys. Chem. Res., 2016, 4, 489505. 
[12] S. Shekarsaraee, B. Kolachahi Sabet, F. Moradi, M. Kazemi, Y. Parvandi, Phys. Chem. Res., 2019, 7, 425-434.

[13] S. Shekarsaraee, Phys. Chem. Res., 2016, 4, 507-518.

[14] F. Ruiz, A. Marcilla, A. Ma Ancheta, C. Rico, Solvent Extr. Ion Exc., 1986, 4, 771-787.

[15] F. Ruiz, A. Marcilla, A. Ma Ancheta, C. Rico, Solvent Extr. Ion Exch., 1986, 4, 789-802.

[16] F. Ruiz, J. Fernández, N. Boluda, AIChE J., 2004, 41, 185-189.

[17] A. Marcilla, F. Ruiz, J. Campos, M. Asensio, Solvent Extr. Ion Exch., 1989, 7, 211-221.

[18] C.H. Harrison, P. Roquero, J. Chem. Eng. Data, 2004, 49, 218-220.

[19] A. Gomez, F. Ruiz, J. Fernandez, E. Torregrosa, Ind. Eng. Chem. Res., 2001, 40, 892-897.

[20] H. Ghanadzadeh Gilani, A. Ghanadzadeh Gilani, S. Shekarsaraee, H. Uslu, Fluid Phase Equilib., 2012, 316, 109-116.

[21] H. Ghanadzadeh Gilani, A. Ghanadzadeh Gilani, S. Shekarsaraee, H. Uslu, J. Chem. Thermodyn., 2012, 53, 52-59.

[22] H. Ghanadzadeh Gilani, A. Ghanadzadeh Gilani, S. Shekarsaraee, Fluid Phase Equilib., 2013, 337, 32-38.

[23] H. Ghanadzadeh Gilani, A. Ghanadzadeh Gilani, S. Shekarsaraee, Thermochim. Acta, 2013, 558, 36-45.

[24] S. Shekarsaraee, J. Chem. Thermodyn., 2017, 104, 16-23.
[25] A. Ghanadzadeh Gilani, A. Najafgholizadeh, B. Mohammadi Khanghah, M. Nasouri Gazani, J. Mol. Liq., 2018, 268, 553-560.

[26] A. Ghanadzadeh Gilani, Nasouri Gazani, B. Mohammadi Khanghah, A. Najafgholizadeh, J. Chem. Thermodyn., 2018, 123, 51-61.

[27] D. Othmer, P. Tobias, Ind. Eng. Chem., 1942, 34, 693-696.

[28] D.B. Hand, J. Phys. Chem., 1930, 34, 19612000.

[29] D.S. Abrams, J.M. Prausnitz, AIChE J., 1975, 21, 116-128.

[30] C. Reichardt, Solvents and Solvent Effects in Organic Chemistry; 3th Ed., Wiley VCH \& Co., 2003; p 420 and pp 645-655.

[31] E. Scholz, Karl Fischer Titration; Springer Verlag: Heidelberg, 1984, pp 3-13.

[32] B.E. Poling, J.M. Prausnitz, J.P. O'Connell, The Properties of Gases and Liquids; fifth ed., McGraw Hill: New York, 2001, pp. 8.75-8.81.

[33] J.M. Sørensen, T. Magnussen, P. Rasmussen, A. Fredenslund, Fluid Phase Equilib., 1979, 2, 297-309.

[34] M.J. Kamlet, J.M. Abboud, M.H. Abraham, R.W. Taft, J. Org. Chem., 1983, 48, 28772887.

[35] H. Ghanadzadeh, A. Ghanadzadeh, S. Asgharzadeh, M. Moghadam, J. Chem. Thermodyn., 2012, 47, 288-294.

How to cite this manuscript: Sina Shekarsaraee, Khadijeh Kazemi, Measurement and Correlation of LLE Data for the Ternary System Water+Phosphoric Acid+1-Pentanol at $278.2 \mathrm{~K}$ and $288.2 \mathrm{~K}$, Adv. J. Chem. A, 2020, 3(4), 432-441.

Copyright (C) 2020 by SPC (Sami Publishing Company)+ is an open access article distributed under the Creative Commons Attribution License, which permits unrestricted use, distribution, and reproduction in any medium, provided the original work is properly cited. 